\title{
Hydraulic Actuator Selection for a Compliant Surgical Bone Drill: A Theoretical Approach
}

\author{
Wouter Gregoor ${ }^{1}$ - Jenny Dankelman ${ }^{1}$ - Christoph Kment ${ }^{2}$ - Gabriëlle J.M. Tuijthof 3,4,* \\ 1 Delft University of Technology, The Netherlands \\ 2 Austrian Center for Medical Innovation and Technology, Austria \\ 3 Zuyd University of Applied Sciences, The Netherlands \\ ${ }^{4}$ ACES, Academic Medical Centre, The Netherlands
}

A compliant bone drill provides advantages over conventional straight drills, because it allows surgical access via a minimally invasive approach. Hydropower allows the transfer of pressurized water with a compliant hose. The goal is to select the hydraulic actuator for this compliant bone drill by reviewing existing actuator principles. The selection was performed with a theoretical analysis. Design requirements were derived from a challenging minimally invasive bone drill procedure, and were set: a speed of $750 \mathrm{rpm}$, a torque of $0.015 \mathrm{Nm}$ and a maximum dimensional volume of $5 \mathrm{~mm} \times 5 \mathrm{~mm} \times 10 \mathrm{~mm}$ to drill $\varnothing 1.5 \mathrm{~mm}$ holes in human bone. A literature search was performed. For each actuator, the fluid flow and the required pressure difference were described as a function of the actuator dimensions and the rotational speed. Selection of the actuator was performed by it meeting the set output power, the torque, realistic input dimensions, and requiring the lowest pressure and number of parts. Existing literature provided six hydraulic actuators: external gear motor, gear ring motor, axial turbine, radial turbine, Pelton wheel, and Ossberger turbine. The latter four are hydrodynamic turbines, which could not meet the rotational speed. The external gear motor was selected for its lowest required pressure difference $\left(11.5 \times 10^{5} \mathrm{~Pa}\right)$ and design simplicity. This theoretical design approach can be used for other applications.

Keywords: orthopaedic procedures, surgical tools, actuator, bone drill, hydraulic

Highlights

- Quantitative design requirements for a compliant minimally invasive surgical bone drill were derived.

- $\quad$ Six hydraulic actuators were reviewed: external gear motor, gear ring motor, axial turbine, radial turbine, Pelton wheel, and Ossberger turbine.

- Theoretical calculation using the quantitative requirements resulted in the selection of the external gear motor as the most feasible actuator.

- The theoretic equations can be applied to select hydraulic actuators for other applications.

\section{INTRODUCTION}

Arthroscopy is minimally invasive surgery performed in human joints. It has tremendous benefits for patients in terms of low morbidity and quick rehabilitation. In this paper, we focus on the arthroscopic microfracture technique, which is the first-line treatment for cartilage lesions in knees, ankles and other joints [1] and [2]. With microfracture, small holes (microfractures) are drilled perpendicular to the cartilage lesion, which eventually forms regenerated fibrocartilage [1] and [2]. The microfracture technique is a typical medical case that reveals technical drawbacks of using straight instruments and predefined access portals in joints: not every surgical site can be reached, and perpendicular drilling is possible in only a few locations in joints [3] and [4]. In the worst case, these drawbacks prevent adequate treatment. From a mechanical viewpoint, two contradictory requirements have to be met: instruments need to be compliant and steerable to reach lesions (flexibility), and they need to be stiff to resist machining forces (rigidity) [1] and [2]. Some solutions were proposed to achieve the above functionality using electromotors and mechanical transmission, but without success [5] to [7]. We explore the feasibility of a different technical principle: the design of a compliant bone drill that is to be powered by a hydraulic actuator. This allows energy transfer to the joint via a compliant hose that carries pressurized water. This design provides the additional advantages that during arthroscopy saline fluid is already used to rinse the joint, and water contributes to the cooling of the drill bit to prevent necrosis [4]. The goal of this study is to select the most suitable miniature hydraulic actuator that transfers hydraulic power to the drill bit and fits within a minimally invasive instrument.

\section{METHODS}

First, the general theory on hydraulic actuators describes the two fundamental working principles (hydrostatic motors and hydrodynamic turbines) 
with mathematical formulas. Second, a review of the literature gives an inventory of actuators. Third, the actuators are evaluated using a theoretical design engineering approach. Calculations are performed with quantitative values derived for the medical case of micro-fracturing, i.e., required output power $P$, the rotational speed $n$, the required torque $T$ and realistic input dimensions. This gives the fluid flow $Q$ and the required pressure difference $\Delta p=p_{\text {in }}-p_{\text {out }}$ per actuator upon which the most suitable is selected.

\subsection{Fundamental Hydraulic Working Principles}

In this study, the presence of losses is neglected and a steady flow of an ideal fluid is assumed [8]. Consequently, the output power equals the input power:

$$
P=T \cdot 2 \pi \cdot \frac{n}{60}=\Delta p \cdot Q
$$

\subsubsection{Hydrostatic Motors}

In hydrostatic motors, a displacement volume $V$ is trapped and transported periodically by moving parts (e.g., gears or vanes) (Fig. 1). The loads on the moving parts transfer in $\Delta p$ to give hydraulic power [8] and [9]. $Q$ follows from [9] (Fig. 1):

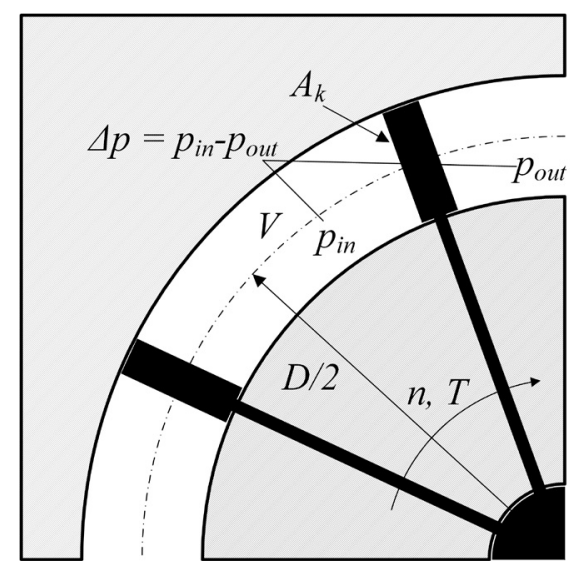

Fig. 1. Schematic drawing of a simplified hydrostatic motor; adapted from [9]

$$
Q=V \cdot \frac{n}{60}=\left(\frac{1}{8} \cdot \pi D \cdot A_{k}\right) \cdot \frac{n}{60},
$$

where $D$ is the diameter and $A_{k}$ is the effective area. Similarly, $\Delta p$ follows from Eqs. (1) and (2) and [9] (Fig. 1):

$$
\Delta p=\frac{P}{Q}=\frac{1}{15} \cdot \frac{T}{D \cdot A_{k}} .
$$

A typical characteristic of hydrostatic motors is that $\Delta p$ is independent of $n$. This implies that $T$ can be set by choosing $\Delta p$ and $Q$ [9].

\subsubsection{Hydrodynamic Turbines}

Hydrodynamic turbines are open structures through which the flow passes. Energy is transferred from the fluid to the turbine by dynamic action [10]. The relative movement exists between the continuous moving fluid and the turbine blades. This creates a momentum exchange [10]. In contrary to the hydrostatic motors, the torque is a function of the rotational speed $T(n)$. Calculation of $Q$ requires the formulation of absolute $\left(C_{\text {in }}\right.$ and $\left.C_{\text {out }}\right)$ and relative $\left(c_{\text {in }}\right.$ and $\left.c_{\text {out }}\right)$ inlet and outlet velocities and their radial and tangential components $\left(C_{R}\right.$ and $C_{T}$ ) (Fig. 2). The direction of the common absolute inlet and outlet velocity $C_{\text {in }}$ and $C_{\text {out }}$ on one blade is indicated by solid thick arrows. The turbine velocities at the inner and outer part of the blades are $U_{\text {in }}$ and $U_{\text {out }}$ (at half of the diameter $D_{\text {out }}$ vs. $D_{\text {in }}$ ). The absolute velocities are decomposed into a tangential $C_{\text {Tin }}$ and $C_{\text {Tout }}$ and radial components $C_{\text {Rin }}$ and $C_{\text {Rout }}$ indicated by dotted arrows. The fluid inlet and outlet angles $\alpha_{\text {in }}$ and $\alpha_{\text {out }}$ and blade angles $\beta_{\text {in }}$ and $\beta_{\text {out }}$ are needed for this decomposition. Finally, the fluid velocities relative to the turbine $c_{\text {in }}$ and $c_{\text {out }}$ are derived and indicated by striped arrows. Fluid enters the hydrodynamic turbine with an absolute velocity $C_{i n}$ at a fluid inlet angle $\alpha_{i n}$. This yields a relative velocity $c_{i n}$ $=C_{i n}-U_{i n}$ with $U_{i n}$ is the inner turbine velocity (Fig. 2 ). The fluid exits with a relative velocity $c_{\text {out }}$ at an angle $\beta_{\text {out }}$. This gives an absolute outlet velocity $C_{\text {out }}$ $=c_{\text {out }}+U_{\text {out }}$ with $U_{\text {out }}$ is the outer turbine velocity at fluid outlet angle $\alpha_{\text {out }}$ (Fig. 2). $Q$ is given by [10]:

$$
Q(n)=\frac{1}{k_{v}} \cdot C_{\text {Rout }}(n) \cdot A_{\text {turbine }} .
$$

With $A_{\text {turbine }}$ is the effective area where the fluid flows through, and $k_{v}$ is a correction factor for the volume that is occupied by the vanes. For the working principle of hydrodynamic turbines, $T(n)$ is derived from Newton's second law of motion in which the mass flow changes over time, and with steady-state tangential absolute fluid velocities $\left(C_{\text {Tin }}\right.$ and $\left.C_{\text {Tout }}\right)$ [10] and [11] (Fig. 2):

$$
\begin{aligned}
T= & m \cdot \frac{d}{d t} \cdot C_{T}(t) \cdot \frac{D}{2}= \\
& Q(n) \cdot \rho \cdot\left(\frac{D_{\text {out }}}{2} \cdot C_{\text {Tin }}(n)+\frac{D_{\text {in }}}{2} \cdot C_{\text {Tout }}(n)\right) .
\end{aligned}
$$

Filling out Eq. (4) in Eq. (5) gives [10]: 


$$
\begin{aligned}
T(n)= & \frac{1}{k_{v}} \cdot C_{\text {Rout }}(n) \cdot A_{\text {turbine }} \cdot \\
& \rho\left(\frac{D_{\text {out }}}{2} \cdot C_{\text {Tin }}(n)+\frac{D_{\text {in }}}{2} \cdot C_{\text {Tout }}(n)\right) .
\end{aligned}
$$

Notice that $C_{T}$ and $C_{R}$ are a function of $n$ and the turbine's dimensions. Subsequently, $\Delta p$ is derived from Bernoulli's equation [10]:

$$
P=\left(\Delta p+\frac{1}{2} \cdot \rho\left(C_{i n}^{2}(n)-C_{o u t}^{2}(n)\right)\right) \cdot Q(n) .
$$

First Eq. (1) is substituted for $P$, followed by Eq. (6) for $T$. Next Eq. (7) is rewritten to give $\Delta p$ [10]:

$$
\begin{aligned}
\Delta p & =\rho\left(\frac{D_{\text {out }}}{2} \cdot C_{\text {Tin }}(n)+\frac{D_{\text {in }}}{2} \cdot C_{\text {Tout }}(n)\right)- \\
& \frac{1}{2} \cdot \rho\left(C_{\text {in }}^{2}(n)-C_{\text {out }}^{2}(n)\right) .
\end{aligned}
$$
turbines.

Thus, $\Delta p$ depends on $n$ for hydrodynamic

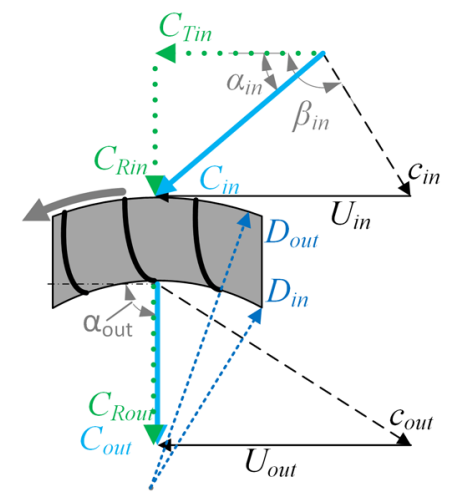

Fig. 2. Schematic drawing of a cross-section of three blades of a radial turbine (grey) to highlight the velocity profile; adapted from [10]

\subsection{Literature Review}

First, surgical instruments were reviewed that use hydrostatic motors and/or hydrodynamic turbines as proposed by the concept. Second, the review was concentrated on general working principles of hydraulic actuators by searching the Scopus database and the library of Delft University of Technology (www.library.tudelft.nl). In Scopus, the following keywords were used without date and language restrictions using OR:

- Hydraulic motor, hydrostatic motor, positive displacement for hydrostatic motors,
- turbomachinery, hydrodynamic, hydraulic turbine, water turbine, impeller for hydrodynamic turbines.

In the TU Delft library collection, the following categories were reviewed:

- EH / Fluid mechanics EHA / Fluid mechanics: general,

- NG / Energy conversion systems NGM / Turbomachinery: general NGN / Hydraulic converters: general NGP / Pump technology: general NGR / Pumps NGS / Hydraulic motors and turbines,

- MG / Design of control systems MGC / Servomechanisms, fluid systems.

\subsection{Requirements Set by Arthroscopic Microfracture Technique}

To perform a quantitative evaluation of the found actuators, requirements were set using the arthroscopic microfracture technique [1] and [2].

\subsubsection{Dimensions}

The suggested dimensions of the standard technique were adopted: a hole diameter of $1.5 \mathrm{~mm}$ and a hole depth of $4 \mathrm{~mm}$ [1]. Thus, the drill bit diameter $D_{\text {drill }}$ was determined to be $1.5 \mathrm{~mm}$ and used to calculate the drilling torque. Additionally, the limited space in human joints sets a maximum height and width of 5 $\mathrm{mm}$ to the embodiment of a hydraulic actuator [12] and [13]. The length of a hydraulic actuator was set at a maximum of $10 \mathrm{~mm}$ to allow manoeuvrability in human joints [13]. These relatively small dimensions pose restrictions because small parts reach their material limits sooner upon loading by relatively high values of $\Delta p$ and $T$. This was taken into account when evaluating the hydraulic actuators.

\subsubsection{Torque}

Literature presents formulas that describe the torque $T$ for drilling in bone [14]:

$$
T=j \cdot f^{y} \cdot \frac{\pi}{4}\left(D_{\text {drill }}\right)^{2} \cdot 1000,
$$

where $f$ is the drilling feed in $\mathrm{mm} / \mathrm{rev}$ and $j, y, x$ and $B$ are constants related to the drill type. Eq. (9) was verified by comparing its calculated outcome to experimental results from other studies [15] and [16]. The results gave the same order of magnitude for $T$ (Table 1). The drilling feed for the microfracture technique was determined according to Sezek [17] 
who indicated that a safe drilling feed of $70 \mathrm{~mm} / \mathrm{min}$ at $n=370 \mathrm{rpm}$ (equals $0.19 \mathrm{~mm} / \mathrm{rev}$ ) avoids necrosis. Filling out $f$, the set $D_{\text {drill }}$ and the drill constants of a standard surgical twist drill bit [14] (i.e. $j=1.6 \times 10^{-2}$, $y=0.39, x=2.2$ and $\left.B=3.8 \times 10^{-4}\right)$ in Eq. (9) gives a $T$ of $0.0015 \mathrm{Nm}$.

Table 1. Bone drilling data; a) gives the calculated drilling torque $T$ using Eq. (9), $D_{\text {drill }}$ and feed $f$ suggested by Wiggins [14]; b) presents the experimentally measured drilling torques; note that the drill diameters are different from the set $D_{\text {drill }}$

\begin{tabular}{lccc}
\hline \multicolumn{1}{c}{ Parameter } & Wiggins [14] $]^{\mathrm{a})}$ & Jacob [15] ${ }^{\mathrm{b})}$ & Tuijthof [16] ${ }^{\mathrm{b})}$ \\
\hline$D_{\text {drill }}[\mathrm{mm}]$ & 2.77 & 3.2 & 3 to 3.2 \\
\hline$f[\mathrm{~mm} / \mathrm{rev}]$ & 0.25 & 0.20 & 0.3 \\
\hline$T[\mathrm{Nm}]$ & 0.06 & 0.07 & 0.02 to 0.12 \\
\hline
\end{tabular}

\subsubsection{Speed, Power and Pressure}

Eq. (9) indicates that the torque is independent of speed. Jacob et al. [15] show that this only holds for rotational speeds above $750 \mathrm{rpm}$. Therefore, the hydraulic actuators were evaluated at $n=750 \mathrm{rpm}$. Filling out $n$ and $T$ in Eq. (1) sets the required power $P$ to be $1.16 \mathrm{~W}$. Finally, we set $\Delta p$ as low as possible to remain below the material limits of conventional materials.

\section{RESULTS}

The literature search yielded no small-sized hydraulic actuators suitable for the use case. Most hydrodynamic turbines are applied on a much larger scale in, for example, hydro-electric power plants. The hydraulic actuators and corresponding mathematical descriptions were derived from four out of ten books [8] to [11]. The discarded books describe overlapping content.

\subsection{Hydrostatic Motors}

Hydrostatic motors can be divided into piston, gear, and vane motors (Fig. 3) [9]. As the names suggest, piston motors work by moving pistons, gear motors work by interlocking gears that trap the fluid volume in the space where the gears do not interlock, and vane motors work by moving vanes that enclose the fluid volume [9].

Given the dimensional requirements, the relative high complexity and large number of small parts of piston and vane motors, only the gear motors were analysed. Furthermore, the gear ring motor does not require a shekel-shaped separation element and can be build smaller in comparison to the internal gear motor (Fig. 3). Therefore, only the external gear motor and the gear ring motor were analyzed.

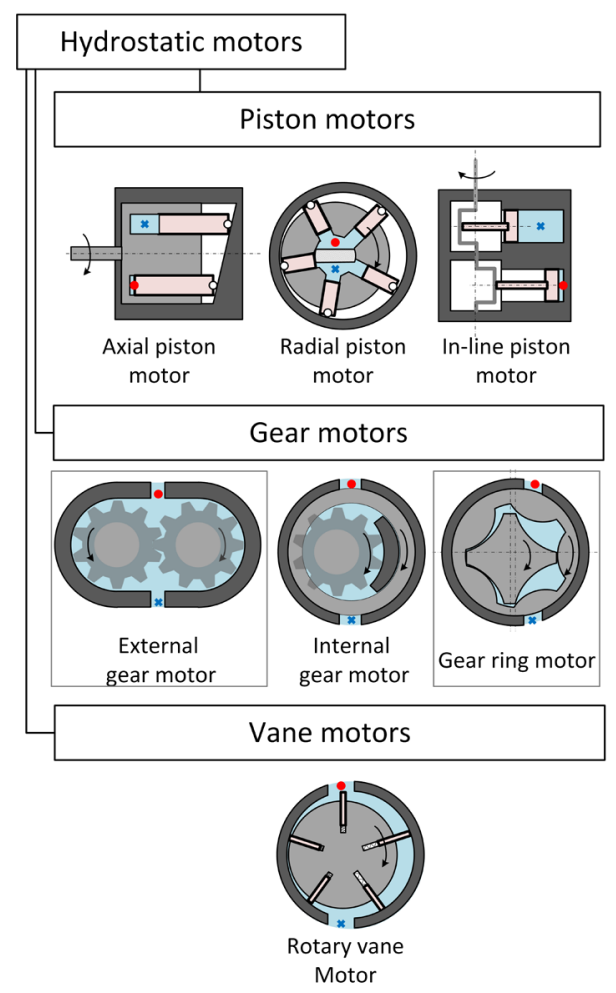

Fig. 3. Overview of hydrostatic motors; for each, a section view is presented indicating the fluid (light blue), the stationary parts (dark grey), the translating parts (pink/thick lines), the rotating parts (light grey) the fluid inlet (red dot) and the fluid outlet (blue cross); adapted from [9]

\subsubsection{External Gear Motor}

The external gear motor works with pressurized fluid entering the motor that causes a distributed force $F_{p}$ acting on the two gears (Fig. 4). Formulating $Q$ (n,dimensions) starts by determining the mean displacement volume $V_{m}$ (Fig. 4). It is assumed that both gears are equally sized, only one teeth pair contributes to the displacement and that the pressure drop occurs over one teeth pair. First, the instantaneous displacement volume $d V$ is derived from the instantaneous work $d W$ [9]:

$$
d W=T_{1} \cdot d \varphi_{1}+T_{2} \cdot d \varphi_{2}=d V \cdot \Delta p .
$$

With $T_{1}$ and $T_{2}$ are the torques on both gears and $d \varphi_{1}$ and $d \varphi_{2}$ their change of angular displacement. They are expressed in the gear diameter $D_{\text {out }}$, the gear width $b$, the number of teeth $z$ and distances $u$ and $x_{a}$ 
(Fig. 4). The change of angular displacement is written as $d \varphi=\omega d t=2 \pi \frac{n}{60} d t$. The gear torques are generated by $F_{p}$ multiplied by moment arm $l$ and can be expressed as (Fig. 4) [9]:

$$
\begin{gathered}
T_{1,2}=F_{p} \cdot l=\Delta p \cdot b \cdot h \cdot \frac{k}{2}= \\
p \cdot \frac{b}{2} \cdot\left[\left(\frac{D_{\text {out }}}{2}\right)^{2}-\left(\frac{D_{\text {out }}}{2} \cdot \frac{2}{z+2}\right)^{2} \pm \frac{D_{\text {out }} \cdot 2 x_{a}}{z+2}-u^{2}\right]
\end{gathered}
$$

$k$ is the length of the projected area of the gear which is not pressurized due to meshing of the teeth and $h$ is the length of the pressurized area (Fig. 4). $k$ and $h$ are expressed in $D_{\text {out }}, z, u$ and $x_{a}$ (Appendix A1). Subsequently, Eq. (10) is rewritten and filled out with Eq. (11) and $d \varphi$ to yield $d V$ [9]:

$d V=b \cdot \pi \frac{n}{30}\left[\left(\frac{1}{2} D_{\text {out }}\right)^{2}-\left(D_{\text {out }} \frac{z}{2(z+2)}\right)^{2}-u^{2}\right] \cdot d t,(12)$

Second, $d V$ changes over the interlocking trajectory of two teeth. For the period of continuous interlocking of these teeth, the tooth pair has to interlock from $u=-w / 2$ till $u=w / 2$ with $w$ being the transverse base pitch [18] (Fig. 4). The $V_{m}$ of the teeth pair over the interlocking trajectory is calculated by integrating Eq. (12) over time [9]:

$$
V_{m}=\int_{-w / 2}^{w / 2} d V=b \cdot 2 \pi \cdot\left(\frac{D_{o u t}}{z+2}\right)^{2} \cdot \frac{z+\sin ^{2} \gamma}{z} .
$$

Solving the integral requires $u$ and $w$ to be expressed in gear dimensions (Appendix A2). Finally, $Q$ is obtained as follows [16]:

$$
Q=z \cdot \frac{n}{60} \cdot V_{m}=\frac{n \cdot b \cdot \pi}{30} \cdot\left(\frac{D_{\text {out }}}{z+2}\right)^{2} \cdot\left(z+\sin ^{2} \gamma\right) .
$$

Filling out the set and chosen values of the geometric parameters as presented in Table 2 in Eq. (14), a fluid flow $Q$ of $0.001 \mathrm{~L} / \mathrm{s}$ is obtained. With $Q$ and $P$ known, $\Delta p$ is calculated with Eq. (1) to be $11.5 \times 10^{5} \mathrm{~Pa}$.

\subsubsection{Gear Ring Motor}

The gear ring motor works by an eccentric inner gear ring (called "pinion") that interlocks with the outer gear ring on one side (Fig. 3). The pinion has one tooth less than the gear ring and rotates as well as the gear ring (gerotor principle). This principle makes use of trochoid toothing which guarantees a seal between the inner and outer teeth and creates a moving displacement volume $\left(V_{s}=A_{s} \cdot b\right)$ opposite the interlocking teeth (Fig. 5) [9]. Next, we define $z$ as the number of teeth of the gear ring. Notice that the pinion always has one tooth less than the gear ring, hence $z_{p}=z-1[9]$.

The general formula of $Q$ is given by the first part of Eq. (14) with the difference that $V_{S}$ is approximated by displacement volume $V_{p}=A_{p} \cdot b$ as follows (Fig. 5) [9]:

$$
Q=z_{p} \cdot \frac{n}{60} \cdot V_{p}=z_{p} \cdot \frac{n}{60} \cdot 2 e \cdot \frac{\pi \cdot D}{z_{p}} \cdot k_{a} \cdot b,
$$

where $e$ is the eccentricity and $k_{a}$ is a correction factor that takes into account the small error that is introduced by the approximation. $k_{a}$ can be expressed in $z$ and $x_{c}(\approx 0.125)$ [9]:

$$
k_{a}=\frac{A_{p}}{A_{s}}=\left(\frac{z_{p}}{z}\right)^{x_{c}} .
$$

The values for $k_{a}$ and the set design parameters from Table 2 were filled out in Eq. (15) to obtain a fluid flow of $5.4 \times 10^{-4} \mathrm{~L} / \mathrm{s}$. With $Q$ and $P$ known, $\Delta p$ is calculated with Eq. (1) to be $21.7 \times 10^{5} \mathrm{~Pa}$.

\subsection{Hydrodynamic Turbines}

Hydrodynamic turbines can be divided into reaction and impulse turbines (Fig. 6) [10]. Reaction turbines exist in axial and radial configurations and are fully submerged [10]. The water is accelerated or

Table 2. Parameters that were used to calculate $n, Q$ and $\Delta p$ for the actuators. The actuators' diameters $\left(D_{\text {out }}\right.$ and $\left.D_{\text {in }}\right)$ and width $b$ were derived from the set requirements; the number of teeth $(z$ and $z_{p}$ ), the various blade angles and $k_{v}$ were chosen to reach the highest efficiency

\begin{tabular}{lcccccc}
\hline Actuator & $\begin{array}{c}D_{\text {out }} \\
{[\mathrm{m}]}\end{array}$ & $\begin{array}{c}D_{\text {in }} \\
{[\mathrm{m}]}\end{array}$ & $\begin{array}{c}b \\
{[\mathrm{~m}]}\end{array}$ & $z$ & $z_{p}$ & $\begin{array}{c}\gamma \\
{\left[{ }^{\circ}\right]}\end{array}$ \\
\hline $\begin{array}{l}\text { External } \\
\text { gear }\end{array}$ & 0.005 & - & 0.005 & 5 & - & $20[18]$ \\
\hline $\begin{array}{l}\text { Gear } \\
\text { ring }\end{array}$ & 0.004 & - & 0.005 & 6 & 5 & $20[18]$ \\
\hline & & & & $\begin{array}{c}\beta_{\text {in }} \\
{\left[{ }^{\circ}\right]}\end{array}$ & $\begin{array}{c}\beta_{\text {out }} \\
{\left[{ }^{\circ}\right]}\end{array}$ & $k_{v}$ \\
\hline $\begin{array}{l}\text { Axial } \\
\text { turbine }\end{array}$ & 0.005 & 0.002 & - & 90 & 78 & 1.2 \\
\hline $\begin{array}{l}\text { Radial } \\
\text { turbine }\end{array}$ & 0.005 & 0.002 & 0.005 & 90 & 70 & 1.2 \\
\hline $\begin{array}{l}\text { Pelton } \\
\text { wheel }\end{array}$ & 0.005 & 0.003 & - & 0 & - & - \\
\hline $\begin{array}{l}\text { Ossb. } \\
\text { turbine }\end{array}$ & 0.005 & 0.003 & - & - & $16[20]$ & - \\
\hline
\end{tabular}




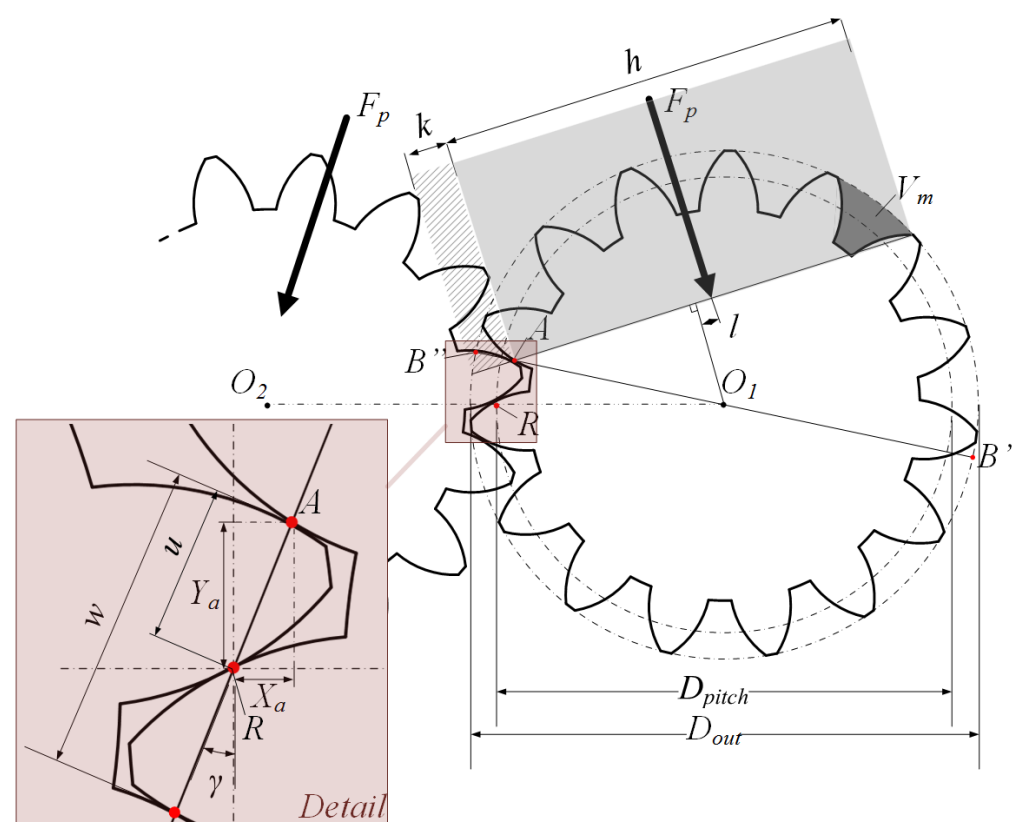

Fig. 4. Definition of the important geometric parameters of the external gear motor; the hydrostatic pressure area is indicated by light grey, the area of no pressure due to meshing of the teeth is hatched. Indicated are the distributed force $f_{p}$, the moment arm $I$, the roll point $R$, the contact point $A$, the gear centres $\left(O_{1}\right.$ and $\left.O_{2}\right)$, the mean displacement area $V_{m}$, distances $h$ and $k$ : part of the interlocking teeth are enlarged in a detail drawing showing points $R$ and $A$, pressure angle $\gamma$ and distances $u$ and $w$; adapted from [9]

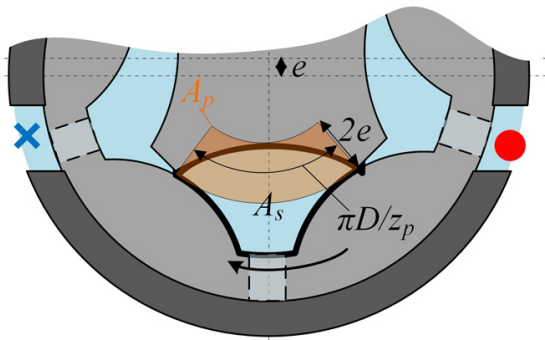

Fig. 5. Cross section of a part of the gear ring motor; both gear rings (light grey) rotate in clockwise direction in the housing (dark grey); pressurized fluid enters the motor on the right (red dot) and enters the displacement volume via internal channels distributed along the gear ring; the fluid leaves the motor at the left side (blue cross); part of the pinion is shown that entraps the displacement

area $A_{S}$ (thick lines) together with the outer gear ring;

the approximate displacement area $A_{p}$ is coloured orange (thin lines); adapted from [9]

decelerated over the blades. The force that causes the acceleration and deceleration is generated by the fluid pressure. The result is that the fluid velocity is changed from inlet to outlet. The impulse turbines operate at atmospheric pressure. Two types are present: the Pelton wheel and Ossberger turbine (Fig. 6). The working principle is that the water's pressure (potential energy) is converted to water's kinetic energy by a nozzle that causes a water jet to hit the blades. This results in a force on the bucket blade that together with the wheel's diameter creates a torque on the turbine wheel (Figs. 6 and 7). The impulse turbines

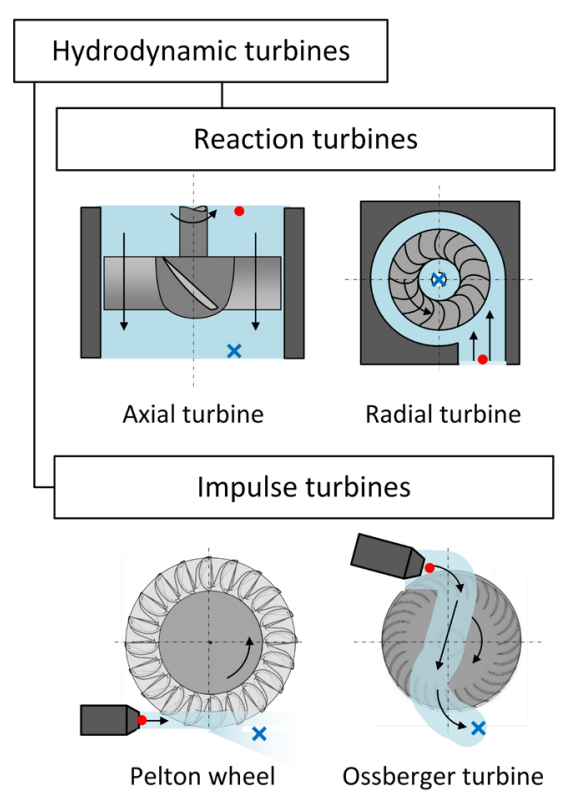

Fig. 6. Overview of hydrodynamic turbines; for each, a section view is presented indicating the fluid (light blue), the stationary parts (dark grey), the rotating parts (light grey), the fluid inlet (red dot) and the fluid outlet (blue cross); adapted from [10] 
do not require a housing, whereas reaction turbines require a housing since they are fully submerged.

As the total pressure drop takes place in the nozzle, impulse turbines do not require a housing. Despite their different nature of energy transfer, the mathematical descriptions of reaction and impulse turbines are described in analogy to yield the $n$ and $Q$. Since $T$ is dependent on $n$, the set torque is used to calculate the rotational speed.

\subsubsection{Radial Turbine}

Following the general approach, first $Q$ is calculated with Eq. (4) [10]. This requires $C_{\text {Rout }}$ to be expressed as a function of $n$ (see Appendix B1: Eq. (36)). The direction of the absolute inlet and outlet fluid velocity $C_{\text {in }}$ and $C_{\text {out }}$ on one blade is indicated by solid thick arrows (Fig. 7). The turbine velocities at the inner and outer part of the blades are $U_{\text {in }}$ and $U_{\text {out }}$ (at half of the diameter $D_{\text {in }}$ vs. $D_{\text {out }}$ ). The absolute velocities are decomposed into a tangential $C_{T i n}$ and $C_{\text {Tout }}$, and in the case of an axial turbine axial components $C_{A i n}$ and $C_{\text {Aout }}$ or in case of a radial turbine in radial components $C_{R i n}$ and $C_{\text {Rout }}$ indicated by dotted green arrows. The fluid inlet and outlet angles $\alpha_{\text {in }}$ and $\alpha_{\text {out }}$ and blade angles $\beta_{\text {in }}$ and $\beta_{\text {out }}$ are needed for this decomposition. Finally, the fluid velocities relative to the turbine $c_{i n}$ and $c_{\text {out }}$ are derived and indicated by striped arrows. $C_{\text {Rout }}(n)$ is substituted in Eq. (4):

$$
Q(n)=\frac{1}{k_{v}} \cdot \frac{D_{\text {in }} \cdot \pi \cdot n}{60} \cdot \tan \left(180^{\circ}-\beta_{\text {out }}\right) \cdot D_{\text {in }} \cdot \pi \cdot b .
$$

Second, to express $T(n)$, all fluid velocities $C_{\text {Rout }}$, $C_{\text {Tout }}, C_{\text {Rin }}$, and $C_{\text {Tin }}$ are described as function of $n$ (see Appendix B1). Substituting Eq. (17) and (39) and $C_{\text {Tout }}=0$ in Eq. (6) yields:

$$
\begin{gathered}
T(n)= \\
\frac{\pi \cdot b \cdot k_{\beta} \cdot D_{\text {in }}^{2} \cdot D_{\text {out }}^{2}}{2 k_{v}} \tan \left(180^{\circ}-\beta_{\text {in }}\right) \cdot \rho \cdot\left(\frac{\pi \cdot n}{60}\right)^{2},
\end{gathered}
$$

$k_{\beta}$ is the constant factor calculated from the in- and outlet blade angles. Finally, $\Delta p$ was determined by substituting Eqs. (36), (38) and (40) in Eq. (8):

$$
\begin{gathered}
\Delta p=\frac{D_{\text {out }}^{2} \cdot k_{\beta 2}\left(1-\frac{1}{2} \cdot k_{\beta 2}\right.}{4} \cdot \rho \cdot\left(\frac{2 \pi \cdot n}{60}\right)^{2}- \\
\frac{\tan \left(180^{\circ}-\beta_{\text {out }}\right)^{2}}{8}\left(\left(\frac{1}{k_{v}} \cdot \frac{D_{\text {in }}^{2}}{D_{\text {out }}}\right)^{2}-D_{\text {in }}^{2}\right) \cdot \rho \cdot\left(\frac{2 \pi \cdot n}{60}\right)^{2} \cdot
\end{gathered}
$$

The set torque and the values of the input parameters (Table 2) were filled out in Eq. (18) to give an $n$ of $55160 \mathrm{rpm}$. The value of $n$ was used to calculate $Q$ with Eq. (17): $0.42 \mathrm{~L} / \mathrm{s}$. Finally, filling out all values in Eq. (19) yields a $\Delta p$ of $2.1 \times 10^{5} \mathrm{~Pa}$.

\subsubsection{Axial Turbine}

Following the general approach, first $Q$ is calculated with Eq. (4) [10]. This requires $C_{\text {Aout }}$ to be expressed as a function of $n$ (see Appendix B2: Eq. (43)) and substituted in Eq. (4):

$$
\begin{gathered}
Q(n)=\frac{1}{k_{v}} \cdot \frac{D_{\text {out }}+D_{\text {in }}}{2} \cdot \frac{\pi \cdot n}{60} . \\
\tan \left(180^{\circ}-\beta_{\text {out }}\right) \cdot \frac{\pi}{4}\left({D_{\text {out }}}^{2}-D_{\text {in }}{ }^{2}\right) .
\end{gathered}
$$

Second, to express $T(n)$, all fluid velocities $C_{A o u t}$, $C_{\text {Tout }}, C_{A i n}$, and $C_{T i n}$ are described as function of $n$ (see details Appendix B2). Substituting Eqs. (20) and (44) and $C_{\text {Tout }}=0$ in Eq. (6) yields:

$$
\begin{aligned}
& T(n)=\frac{\pi \cdot D_{\text {out }} \cdot k_{\beta} \cdot \tan \left(180^{\circ}-\beta_{\text {out }}\right)}{8 k_{v}} \\
& \cdot \frac{D_{\text {out }}+D_{\text {in }}}{4} \cdot\left(D_{\text {out }}^{2}-D_{\text {in }}^{2}\right) \cdot \rho \cdot\left(2 \pi \cdot \frac{n}{60}\right)^{2} .
\end{aligned}
$$

Finally, $\Delta p$ was determined. First, the absolute fluid velocities were calculated using the Pythagorean theorem (Fig. 7a). Second, Eqs. (43) and (44) and the absolute fluid velocities were filled out in Eq. (8):
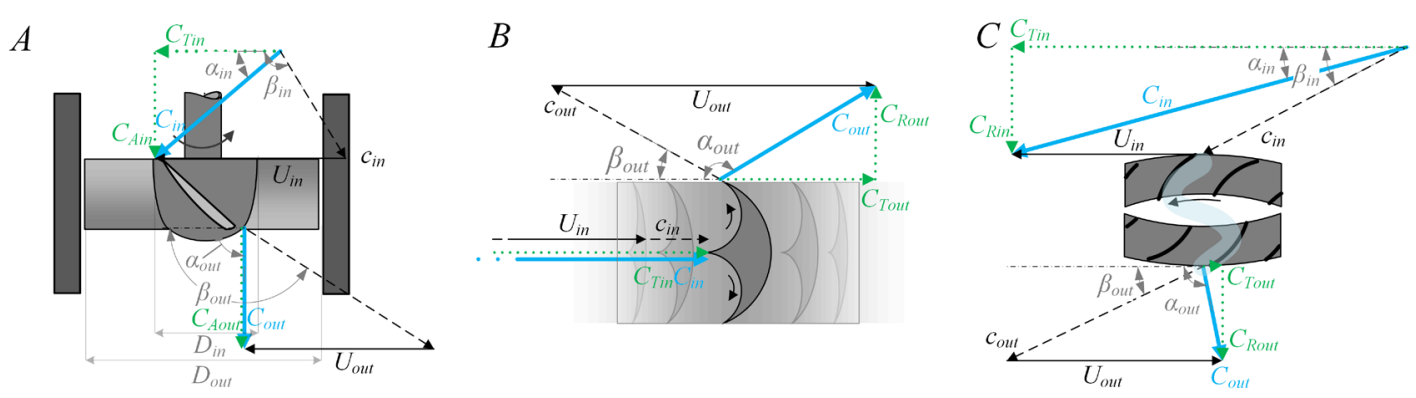

Fig. 7. Velocity profiles of a) an axial turbine, b) a Pelton wheel and c) an Ossberger turbine; adapted from [10] 


$$
\Delta p=k_{\beta} \cdot\left(1-\frac{\rho}{2} \cdot k_{\beta}\right) \cdot\left(\frac{D_{o u t}+D_{i n}}{4}\right)^{2} \cdot\left(2 \pi \cdot \frac{n}{60}\right)^{2}
$$

The set torque and the values of the input parameters (Table 2) were filled out in Eq. (21) to give an $n$ of $62825 \mathrm{rpm}$. The value of $n$ was used to calculate $Q$ with Eq. (20): $0.74 \mathrm{~L} / \mathrm{s}$. Finally, filling out all values in Eq. (22) gives a $\Delta p$ of $15.3 \times 10^{5} \mathrm{~Pa}$.

\subsubsection{Pelton Wheel}

$Q$ is fully defined by the absolute inlet fluid velocity $C_{i n}$ and the nozzle diameter $D_{j}[19]$ :

$$
Q=C_{i n} \cdot \pi\left(\frac{D_{j}}{2}\right)^{2}
$$

Using Fig. 7b, the tangential inlet and outlet velocities are determined [19]:

$$
\begin{gathered}
C_{\text {Tin }}=C_{\text {in }}, \\
C_{\text {Tout }}=c_{\text {out }} \cdot \cos \left(\beta_{\text {out }}\right)-U_{\text {out }} .
\end{gathered}
$$

With the bucket velocity $U_{\text {out }}$ is defined as $\frac{D}{2} \cdot 2 \pi \cdot \frac{n}{60}$, and $c_{\text {out }}$ is the outlet water jet velocity relative to the bucket velocity. $C_{i n}$ is set to $2 U_{\text {out }}$, since this ratio gives the maximum output power [19]. Since $C_{\text {in }}$ is twice $U_{\text {out }}, C_{\text {out }}$ of the emerging water jet in the plane of the wheel is zero (provided that $\beta_{\text {out }}=0$ ). This means that the complete momentum of the inlet water jet is transferred into work and water will effectively fall off the trailing edge of the buckets. With this assumption, $T(n)$ can be fully expressed:

$$
\begin{gathered}
T(n)= \\
C_{\text {in }} \cdot \pi\left(\frac{D_{j}}{2}\right)^{2} \cdot \rho \cdot \frac{D}{2} \cdot\left(C_{\text {in }}+\left(c_{\text {in }} \cdot \cos \left(\beta_{\text {out }}\right)-U_{\text {out }}\right)\right)= \\
\pi\left(\frac{D_{j}}{2}\right)^{2} \cdot \frac{D^{3}}{4} \cdot\left(1+\cos \left(\beta_{\text {out }}\right)\right) \cdot \rho \cdot\left(2 \pi \cdot \frac{n}{60}\right)^{2} .
\end{gathered}
$$

The set torque and the values of the input parameters (Table 2) were filled out in Eq. (26) to give an $n$ of $22716 \mathrm{rpm}$. The value of $n$ was used to calculate $Q$ with Eq. (23): $0.08 \mathrm{~L} / \mathrm{s}$. Finally, $\Delta p$ over the blades is zero, since a velocity difference is absent between inlet and outlet water jet.

\subsubsection{Ossberger Turbine}

The Ossberger turbine (often referred as cross-flow or Banki turbine) consists of a nozzle and a turbine runner (Fig. 6). It has a high efficiency at low flow rates. Typically, the water jet enters the runner at an angle of 16 degrees to the tangent of the periphery of the wheel [20]. $Q(n)$ and $T(n)$ determined with the same approach as used for the Pelton wheel. In fact, $Q(n)$ is described by Eq. (23).

Using Fig. 7c, the tangential velocities of the inand outlet waterjet are described [20]:

$$
\begin{gathered}
C_{\text {Tin }}=C_{\text {in }} \cdot \cos \left(\alpha_{\text {in }}\right), \\
\left.C_{\text {Tout }}=c_{\text {out }} \cdot \cos \left(\beta_{\text {out }}\right)-U_{\text {out }}\right) .
\end{gathered}
$$

With the bucket velocity $U_{\text {out }}$ is defined as $n \cdot D / 2$, and $\alpha_{i n}$ is the inlet angle of the waterjet. $C_{i n}$ is set to $2 U_{\text {out }} / \cos \alpha_{1}$, since this ratio gives the maximum output power [20]. With these equations, $T(n)$ is described as:

$$
\begin{gathered}
T(n)=\frac{D \cdot n}{\cos \alpha_{1}} \cdot \pi\left(\frac{D_{j}}{2}\right)^{2} \cdot \rho . \\
\left.\left(C_{\text {in }} \cdot \cos \left(\alpha_{\text {in }}\right)+c_{\text {out }} \cdot \cos \left(\beta_{\text {out }}\right)-U_{\text {out }}\right)\right) \cdot \frac{D}{2}= \\
\pi\left(\frac{D_{j}}{2}\right)^{2} \cdot \frac{D^{3}}{2 \cos \alpha_{1}} \cdot \rho \cdot\left(2 \pi \cdot \frac{n}{60}\right)^{2} .
\end{gathered}
$$

The set torque and the values of the input parameters (Table 2) were filled out in Eq. (29) to give an $n$ of $22272 \mathrm{rpm}$. The value of $n$ was used to calculate $Q$ with Eq. (23): $0.09 \mathrm{~L} / \mathrm{s}$. Finally, $\Delta p$ over the blades is zero.

\subsection{Results Summary}

\begin{tabular}{|c|c|c|c|c|}
\hline & & $n$ [rpm] & $Q[\mathrm{~L} / \mathrm{s}]$ & $\Delta p[\mathrm{~Pa}]$ \\
\hline \multirow{2}{*}{$\begin{array}{l}\text { Hydrostatic } \\
\text { motors }\end{array}$} & External gear & 750 & 0.001 & $11.5 \times 10^{5}$ \\
\hline & Gear ring & 750 & 0.0006 & $21.7 \times 10^{5}$ \\
\hline \multirow{4}{*}{$\begin{array}{l}\text { Hydrodynamic } \\
\text { turbines }\end{array}$} & Axial turbine & 62825 & 0.74 & $15.3 \times 10^{5}$ \\
\hline & Radial turbine & 55160 & 0.42 & $2.1 \times 10^{5}$ \\
\hline & Pelton wheel & 22716 & 0.08 & 0 \\
\hline & $\begin{array}{l}\text { Ossberger } \\
\text { turbine }\end{array}$ & 22272 & 0.09 & 0 \\
\hline
\end{tabular}

An overview of the calculated rotational speed, flow and pressure difference for each of the hydraulic actuators is given in Table 3. Due to their different working principles, a difference between hydrostatic motors and hydrodynamic turbines is that the required drilling torque requires a relative high pressure or a high rotational speed and flow, respectively. An exception is the axial turbine which requires both a high $n$ and $\Delta p$.

Table 3. Overview of calculated rotational speed $n$, fluid flow $Q$ and pressure difference $\Delta p$ for the set torque, dimensions and power 


\section{DISCUSSION}

Literature on miniature hydraulic actuators for medical or other applications was not found. Therefore, six conventional hydraulic actuators [8] to [11] were analysed for their applicability in the proposed concept for the compliant bone drill. The medical case of microfracture technique posed a worst-case design scenario: bone is the toughest human tissue to drill, posing a high demand for the required drilling torque and power and the human joint space is very tight, posing a high demand for actuator miniaturization. Following the proposed theoretic approach, the rotational speed, fluid flow and pressure difference were calculated (Table 3). Based on these results, all hydrodynamic turbines are discarded, since they do not meet the set maximum rotational speed of $750 \mathrm{rpm}$. The need for a high rotational speed of the hydrodynamic turbines is explained by Eqs. (6), (18), (21), (26) and (29). The torque is dependent on the rotational speed and the dimensions of the turbine. Since the dimensions need to be small (Table 2), the rotational speed needs to be high [10] and [11]. Eventually, we found one example of a miniature hydraulic turbine applied in a dental drill 'Kern Turbojet' with $n$ of $61000 \mathrm{rpm}$ (later reduced to 45000 $\mathrm{rpm}$ ) and $Q$ of $0.10 \mathrm{~L} / \mathrm{s}$ [21]. This product was not a success, because of its bulkiness and low torque. This finding confirms our calculations and our suggestion to proceed with hydrostatic motors.

The hydrostatic external gear and gear ring motors can generate the set torque and dimensions with reasonable values of the pressure difference (Eq. (4)). The rotational speed $n$ can be set without affecting the required torque [9]. Comparing the external gear motor and the gear ring motor, two aspects are in favour of the external gear motor: the twice-as-lowthan-required pressure difference that adds to the safety margin of the housing and gear materials (Table 3 ), and the simplicity of the design that consists of two gears and a housing. Consequently, this theoretical approach suggests that the external gear motor is most suited to implement in a design for a compliant bone drill.

This theoretical approach poses limitations. First, the efficiency of the actuators was not taken into account. We do expect that the small dimensions will induce relatively high losses that significantly influence the actual required flow and pressure difference [8]. However, since all constructive working principles were miniaturized to the same scale and the losses are assumed to be more or less equal, the relative theoretical comparison as presented
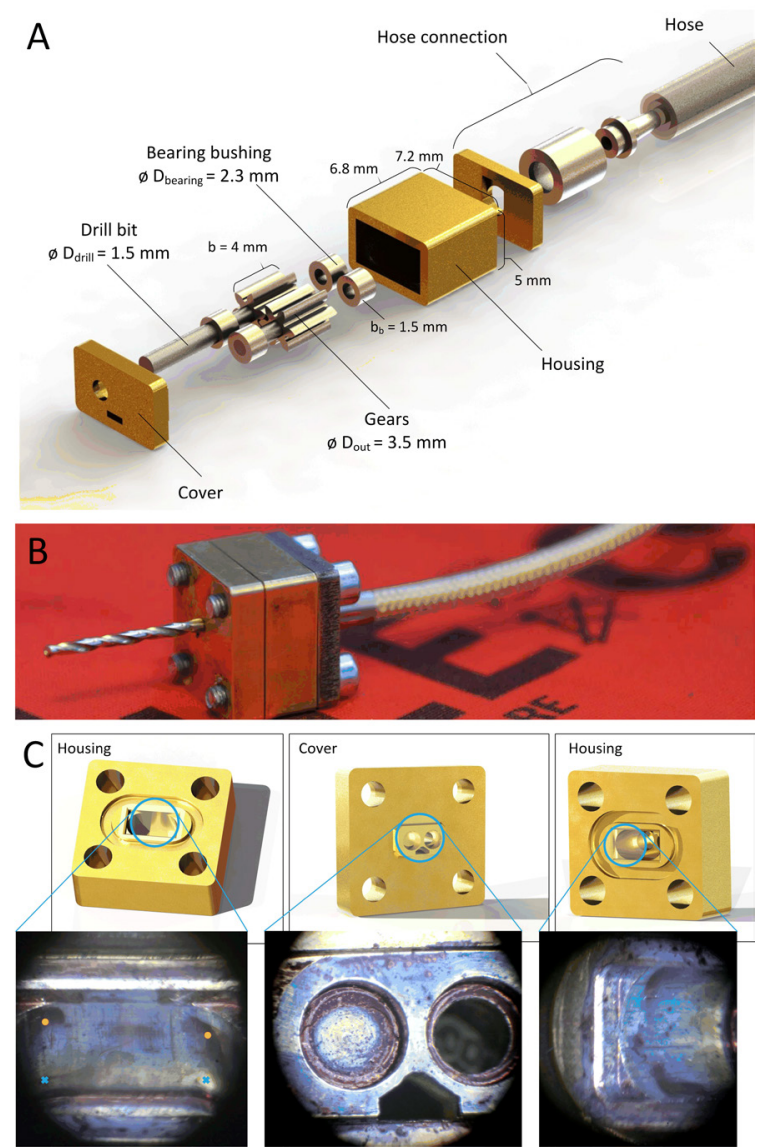

Fig. 8. a) Exploded view of external gear motor prototype with main dimensions, b) assembled prototype, and c) results of leakage test with ink residue left on the axial leakage gap on the cover (middle) and the radial leakage gap of the housing (left and right); more ink residue is present on the outlet side (red dot) than on the inlet side of the actuator (blue cross)

is still useful. Second, we did not alter the designs of the six hydraulic actuators to generate outcome values that would closer match the requirements. This is defendable as one would need to fully redesign all six hydraulic actuators, which was not the scope of this study. However, the designs that required quite some small parts beforehand (Fig. 3) were not included for further analysis. Additionally, the blade angles, pressure angle, teeth, and correction factor (Table 2 ) were chosen such that they would yield the most favourable theoretical outcome. A quick sensitivity analysis of those values indicates that the order of magnitude of the calculated outcome parameters remains the same. However, it is unclear if these values can be achieved in an actual design. Finally, the set value of $750 \mathrm{rpm}$ for the rotational speed was chosen partly because of the lack of available data of the torque for lower speeds [15]. For bone drilling 
without the risk of necrosis, even lower speeds would be recommended [22] with the consequence of a nonlinear increase of the required torque. Still, the external gear motor would compare favourably with the difference that the required pressure difference would increase.

Obviously, the presented analysis is the first important step in developing a compliant hydropowered bone drill. The next step would be to build and to test a miniature external gear motor. Fig. 8 presents an on-scale prototype for which we performed leakage, friction and pressure drop tests. The tests confirmed the challenges to cope with losses, critical geometric and surface tolerances. The prototype's tolerances (H6/h6 fit and clearance of $0.0016 \mathrm{~mm}$ ) and material (brass Ms58 grade and stainless steel 304 grade) were not suitable to achieve a proper working actuator. Further constructive development is required, but this is out of the scope of this paper. The losses in terms of reduced efficiency are acceptable for the intended medical application, but the expected higher required pressure difference could compromise safety. The fact that the energy can be transferred through a compliant hose does provide an advantage above conventional mechanical solutions that are actuated by electromotors.

\section{CONCLUSIONS}

To the best of the authors' knowledge, no systematic analysis of hydraulic actuators has been presented before. The strength of this analysis is that the derived equations can be applied independently from our intended application and complementary requirements to select a hydraulic actuator for other applications. Based on the set requirements for a compliant bone drill, the external gear motor was selected to provide the highest potential.

\section{NOMENCLATURE}

$\gamma$ pressure angle, $\left[{ }^{\circ}\right]$

$\alpha_{\text {in }}$ fluid inlet angle, $\left[{ }^{\circ}\right]$

$\alpha_{\text {out }}$ fluid outlet angle, $\left[{ }^{\circ}\right]$

$\beta_{\text {in }}$ blade inlet angle, $\left[^{\circ}\right]$

$\beta_{\text {out }}$ blade outlet angle, $\left[{ }^{\circ}\right]$

$\Delta p$ pressure difference, $[\mathrm{Pa}]$

$\Delta C$ velocity difference, $[\mathrm{m} / \mathrm{s}]$

$\overline{O A}$ distance contact point - gear centre point, [m]

$d \varphi$ change of angular displacement, [rad]

$\rho$ density, $\left[\mathrm{kg} / \mathrm{m}^{3}\right]$

$A_{k}$ effective area $\left[\mathrm{m}^{2}\right]$ or water jet area, $\left[\mathrm{m}^{2}\right]$

$A_{p}$ approximated gear ring displacement area, [ $\left.\mathrm{m}^{2}\right]$
$A_{s}$ gear ring displacement area, $\left[\mathrm{m}^{2}\right]$

$B$ drill type constant, [-]

$b$ gear width or turbine width, [m]

c fluid velocity relative to turbine, $[\mathrm{m} / \mathrm{s}]$

$C_{\text {in }}$ inlet fluid velocity, $[\mathrm{m} / \mathrm{s}]$

$C_{\text {out }}$ outlet fluid velocity, $[\mathrm{m} / \mathrm{s}]$

$C_{A}$ axial component of the fluid velocity, [m/s]

$C_{R}$ radial component of the fluid velocity, $[\mathrm{m} / \mathrm{s}]$

$C_{T}$ tangential component of the fluid velocity, [m/s]

$D$ diameter, [m]

$D_{\text {drill }}$ drill diameter, [m]

$D_{\text {in }}$ inner diameter, [m]

$D_{j}$ nozzle diameter, [m]

$D_{\text {pitch }}$ pitch diameter, [m]

$D_{\text {out }}$ outer diameter, $[\mathrm{m}]$

$d W$ instantaneous work, [J]

$d V$ instantaneous displacement volume, $\left[\mathrm{m}^{3}\right]$

$e$ eccentricity, [m]

$f$ drilling feed, [mm/rev]

$F$ force, [N]

$F_{p}$ force exerted by fluid pressure, $[\mathrm{N}]$

$F_{\text {thrust }}$ thrust force, $[\mathrm{N}]$

$h$ length of the pressure area $\left(A_{k}\right),[\mathrm{m}]$

$j$ drill type constant, [-]

$k$ length of the projected area of the gear which is not pressurized due to meshing of the teeth, [m]

$k_{\beta}$ constant factor of the in- and outlet blade angles, (Appendix B1)

$k_{a}$ area difference correction factor, [-]

$k_{v}$ vane volume correction factor, [-]

$l$ moment arm, [m]

$m$ mass, $[\mathrm{kg}]$

$n$ rotational speed, [rpm]

$P$ power, [W]

$R$ roll point, [-]

$p_{\text {in }}$ inlet pressure, $[\mathrm{Pa}]$

$p_{\text {out }}$ outlet pressure, $[\mathrm{Pa}]$

$Q$ flow, $\left[\mathrm{m}^{3 / \mathrm{s}}\right]$

$T$ torque, $[\mathrm{Nm}]$

$w$ transverse base pitch, $[\mathrm{m}]$

$u \quad$ distance roll point - contact point, [m]

$U_{\text {in }}$ inlet turbine velocity, $[\mathrm{m} / \mathrm{s}]$

$U_{\text {out }}$ outlet turbine velocity, $[\mathrm{m} / \mathrm{s}]$

$V$ displacement volume, $\left[\mathrm{m}^{3}\right]$

$V_{m}$ mean displacement volume, $\left[\mathrm{m}^{3}\right]$

$w$ transverse base pitch, [m]

$x$ drill type constant, [-]

$x_{A}$ horizontal contact point distance, [m]

$x_{c}$ area correction factor coefficient, [-]

$y_{A}$ vertical contact point to distance, $[\mathrm{m}]$

$y$ drill type constant, [-]

$z$ number of gear teeth, [-]

$z_{p} \quad$ number of pinion teeth, [-] 


\section{REFERENCES}

[1] Steadman, J.R., Rodkey, W G., Briggs, K.K. (2010). Microfracture: Its history and experience of the developing surgeon. Cartilage, vol. 1, no. 2, p. 78-86, DOl:10.1177/1947603510365533.

[2] Van Bergen, C.J.A., De Leeuw, P.A.J., Van Dijk, C.N. (2009). Potential pitfall in the microfracturing technique during the arthroscopic treatment of an osteochondral lesion. Knee Surgery, Sports Traumatology. Arthroscopy, vol. 17, no. 2, p. 184-187, D0l:10.1007/s00167-008-0594-y.

[3] Yan Nai, T., Herder, J.L., Tuijthof, G.J. M. (2011). Steerable mechanical joint for high load transmission in minimally invasive instruments. Journal of Medical Devices, Transactions of the ASME, vol. 5, no. 3, p. 034503-034503-6, DOI:10.1115/1.4004649.

[4] den Dunnen, S., Mulder, L., Kerkhoffs, G.M.M.J., Dankelman, J., Tuijthof, G.J.M. (2013). Waterjet drilling in porcine bone: The effect of the nozzle diameter and bone architecture on the hole dimensions. Journal of the Mechanical Behavior of Biomedical Materials, vol. 27, p. 84-93, D0l:10.1016/j. jmbbm.2013.06.012.

[5] Hacker, R.L., Van Wyk, R.A., Heisler, G.R., (2011). Rotary SHAVER with Improved Connection between Flexible and Rigid Rotatable Tubes. U.S. Patent 7993360,, USPTO, Washington.

[6] Fucci, J., Dinger, F.B., Trott, A.F., Adams, K.M., Mazurek, W.F. (1995). Bendable Variable Angle Rotating Shaver. U.S. Patent 5411514, USPTO, Washington.

[7] Daniel, S.C., Juknelis, A.J., Kauker, B.J., (1995). Arthroscopic cutter Having Curved Rotatable Drive. U.S. Patent 5437630A, USPTO, Washington.

[8] White, F.M. (2008). Fluid Mechanics. McGraw-Hill, New-York.

[9] Ivantysyn, J., Ivantysynova, M. (1993). Hydrostatische Pumpen und Motoren: Konstruktion und Berechnung. Vogel Business Media, Würzburg.

[10] Bohl, W. (1994). Strömungsmaschinen 1-Aufbau und Wirkungsweise. Vogel Business Media, Würzburg.

[11] Dixon, S.L. (2005). Fluid Mechanics and Thermodynamics of Turbomachinery. Butterworth-Heinemann, Oxford.

[12] Dowdy, P.A., Watson, B.V., Amendola, A., Brown, J.D. (1996). Noninvasive ankle distraction: Relationship between force, magnitude of distraction, and nerve conduction abnormalities. Arthroscopy: The Journal of Arthroscopic and Related Surgery, vol. 12, no. 1, p. 64-69, D0l:10.1016/S0749-8063(96)902212.

[13] Tuijthof, G.J.M., Herder, J.L., Van Dijk, C. N., Pistecky, P.V. (2004). A compliant instrument for arthroscopic joint fusion. Proceedings of the ASME Design Engineering Technical Conference, p. 397-405, D0I:10.1115/DETC2004-57148.

[14] Wiggins, K.L., Malkin, S. (1976). Drilling of bone. Journal of Biomechanics, vol. 9, no. 9, p. 553-559, Dol:10.1016/00219290(76)90095-6.

[15] Jacob, C.H., Berry, J.T., Pope, M.H., Hoaglund, F.T. (1976). A study of the bone machining process-Drilling. Journal of Biomechanics, vol. 9, no. 5, p. 343-349, Dol:10.1016/00219290(76)90056-7.

[16] Tuijthof, G.J.M., Frühwirt, C., Kment, C. (2013). Influence of tool geometry on drilling performance of cortical and trabecular bone. Medical Engineering and Physics, vol. 35, no. 8, p. 1165-1172, Dol:10.1016/j.medengphy.2012.12.004.

[17] Sezek, S., Aksakal, B., Karaca, F. (2012). Influence of drill parameters on bone temperature and necrosis: A FEM modelling and in vitro experiments. Computational Materials Science, vol. 60, p. 13-18, D0l:10.1016/j. commatsci.2012.03.012.

[18] Maitra, G.M. (1994). Handbook of Gear Design. Tata McGrawHill Education, Nodia.

[19] Amberger, R. (2014). Pelton wheel water turbine. from: $h t t p: / /$ people.rit.edu/rfaite/courses/tflab/Cussons/pelton/pelton. htm, accessed on 13-06-2014.

[20] Mockmore, C.A., Merryfield, F. (1949). The Banki Water Turbine. Bulletin Series, no. 25, Engineering Experiment Station, Oregon State System of Higher Education, Oregon.

[21] Stephens R.R. (1987). Dental handpiece history. Australian Dental Journal, vol. 32, no. 1, p. 58-62, D0I:10.1111/j.1834-7819.1987.tb01279.x.

[22] Soriano, J., Garay, A., Aristimu-0, P., Iriarte, L.M., Eguren, J.A., Arrazola, P.J. (2013). Effects of rotational speed, feed rate and tool type on temperatures and cutting forces when drilling bovine cortical bone. Machining Science and Technology, vol. 17, no. 4, p. 611-636, Dol:10.1080/10910344.2013.837353.

\section{APPENDIX A1 EXTERNAL GEAR MOTOR}

Distances $k$ and $h$ were rewritten in two steps. First, using the intersection cord theorem, the multiplication of $h$ and $k$ (Eq. (11)) is expressed as [9]:

$$
\begin{aligned}
h \cdot k=\overline{A B^{\prime}} \cdot \overline{A B^{\prime \prime}} & =\left(\frac{1}{2} D_{\text {out }}+\overline{O_{1} A}\right) \cdot\left(\frac{1}{2} D_{\text {out }}-\overline{O_{1} A}\right)= \\
& \left(\frac{1}{2} D_{\text {out }}\right)^{2}-{\overline{O_{1} A}}^{2} .
\end{aligned}
$$

Second, a local coordinate system is placed in roll point $R$ (Fig. 4) defining $u$ as the distance of point $A$ to point $R . \overline{O_{1} A}$ is expressed following the Pythagorean theorem and by substituting $D_{\text {pitch }}$ with $D_{\text {out }} \cdot z /(z+2)$ (Fig. 4):

$$
\begin{gathered}
{\overline{O_{1} A}}^{2}=\left(\frac{1}{2} D_{\text {pitch }}-x_{A}\right)^{2}+y_{A}^{2}= \\
\left(D_{\text {out }} \cdot \frac{z}{2(z+2)}\right)^{2}-D_{\text {out }} \cdot \frac{z}{z+2} \cdot x_{A}+u^{2} .
\end{gathered}
$$

Analogously, $\overline{\mathrm{O}_{2} \mathrm{~A}}$ is derived for the second gear:

$$
\begin{gathered}
{\overline{O_{2} A}}^{2}=\left(\frac{1}{2} D_{\text {pitch }}+x_{A}\right)^{2}+y_{A}^{2}= \\
\left(D_{\text {out }} \cdot \frac{z}{2(z+2)}\right)^{2}+D_{\text {out }} \cdot \frac{z}{z+2} \cdot x_{A}+u^{2} .
\end{gathered}
$$

Finally, Eqs. (31) and (32) are filled out in Eq. (30), which in turn is filled out in Eq. (11). 


\section{APPENDIX A2 GEAR RING MOTOR}

To solve the integration of Eq. (13) some parameters need to be expressed in the gear dimensions. For involute gear, point $A$ moves with a constant speed over the line of action that equals the direction of $u$ (Fig. 4) [9]:

$$
\frac{d u}{d t}=D_{\text {out }} \frac{z}{2(z+2)} \leq \cdot \cos \gamma \cdot 2 \pi \cdot \frac{n}{60} .
$$

With $\gamma$ is the pressure angle (Fig. 4). Eq. (33) is rewritten to express $d t$ in $d u$. Furthermore, for involute gear with equal teeth and no profile shift, $w$ can be expressed as (Fig. 4) [9]:

$$
w=\frac{\pi \cdot D_{o u t}}{z} \cdot \cos \gamma
$$

Substituting the expressions for $d t$ and $w$ in Eq. (13) allows solving the integral .

\section{APPENDIX B1 RADIAL TURBINE}

1. Using Fig. 2, $C_{\text {Rout }}$ is expressed as [10]:

$$
C_{\text {Rout }}=U_{\text {out }} \cdot \tan \left(180^{\circ}-\beta_{\text {out }}\right) \text {. }
$$

Subsequently, $C_{\text {Rout }}$ can be written as function of $n$ by substituting $U_{\text {out }}$ as follows [10]:

$$
C_{\text {Rout }}(n)=\frac{D_{\text {in }}}{2} \cdot \frac{2 \pi \cdot n}{60} \cdot \tan \left(180^{\circ}-\beta_{\text {out }}\right) .
$$

2. Using Fig. 2 , the radial inlet fluid velocity $\left(C_{R i n}\right)$ can be expressed as [10]:

$$
C_{\text {Rin }}=\frac{Q(n)}{D_{\text {out }} \cdot \pi \cdot b} .
$$

Substituting Eq. (17) as expression of $Q(n)$ yields:

$$
C_{\text {Rin }}(n)=\frac{1}{k_{v}} \cdot \frac{D_{\text {in }}{ }^{2}}{D_{\text {out }}} \cdot \tan \left(180^{\circ}-\beta_{\text {out }}\right) \cdot \frac{\pi \cdot n}{60} \text {. }
$$

3. Using Fig. 2, the tangential inlet fluid velocity $\left(C_{T i n}\right)$ can be expressed as:

$$
C_{\text {Tin }}=U_{\text {in }}-\left(\frac{C_{R i n}(n)}{\tan \left(180^{\circ}-\beta_{\text {in }}\right)}\right) .
$$

Subsequently, $C_{T i n}$ can be written as function of $n$ by substituting $U_{\text {in }}$ as and Eq. (38) [10]:

$$
\begin{gathered}
C_{\text {Tin }}=\frac{D_{\text {out }} \cdot \pi \cdot n}{60}\left(1-\frac{1}{k_{v}} \cdot \frac{D_{\text {in }}{ }^{2}}{D_{\text {out }}{ }^{2}} \cdot \frac{\tan \left(180^{\circ}-\beta_{\text {out }}\right)}{\tan \left(180^{\circ}-\beta_{\text {in }}\right)}\right)= \\
\frac{D_{\text {out }} \cdot \pi \cdot n}{60} \cdot k_{\beta} .
\end{gathered}
$$

With $k_{\beta}$ is de constant term that results from the blade angle configuration.

4. Finally, Fig. 2 indicates that $C_{\text {Tout }}$ is zero.

\section{APPENDIX B2 AXIAL TURBINE}

1. Using Fig. 7 a, the axial components of the in- and outlet fluid velocities $C_{A i n}$ and $C_{A o u t}$ are given:

$$
C_{\text {Aout }}(n)=C_{\text {Ain }}(n)=U_{\text {in }} \cdot \tan \left(180^{\circ}-\beta_{\text {out }}\right) \text {. }
$$

Next, the turbine velocity $U$ is described (Fig. 7a) [10]:

$$
U_{\text {in }}=U_{\text {out }}=\frac{1}{2} \cdot \frac{D_{\text {out }}+D_{\text {in }}}{2} \cdot \frac{2 \pi \cdot n}{60} .
$$

Substituting Eq. (42) in Eq. (41) yields:

$$
C_{\text {Tin }}=\frac{D_{\text {out }}+D_{\text {in }}}{2} \cdot \frac{\pi \cdot n}{60}\left(1-\frac{\tan \left(180^{\circ}-\beta_{\text {out }}\right)}{\tan \left(180^{\circ}-\beta_{\text {in }}\right)}\right) \text {. }
$$

2. Using Eq. (39) and substituting Eq. (42), $C_{\text {Tin }}$ is [10]:

$$
C_{\text {Tin }}=\frac{D_{\text {out }}+D_{\text {in }}}{2} \cdot \frac{\pi \cdot n}{60}\left(1-\frac{\tan \left(180^{\circ}-\beta_{\text {out }}\right)}{\tan \left(180^{\circ}-\beta_{\text {in }}\right)}\right) .
$$

3. Finally, Fig. $7 \mathrm{a}$ indicates that $C_{\text {Tout }}$ is zero, analogous to the radial turbine. 